\title{
Research Paper \\ The Effectiveness of Systematic Desensitization and Self-Regulating on Students' Internet Addiction
}

\author{
Samereh Asadi Majareh ${ }^{1}$, Leila Moghtader ${ }^{* 1}$, Seyedeh Maryam Mousavi ${ }^{2}$ \\ 1. Assistant Professor, Department of Psychology, Rasht Branch, Islamic Azad University, Rasht, Iran \\ 2. Assistant Professor, Department of Nursing, Rasht Branch, Islamic Azad University, Rasht, Iran
}

Citation: Asadi Majareh S, Moghtader L, Mousavi SM. The effectiveness of systematic desensitization and self-regulating on students' internet addiction. J Child Ment Health. 2021; 8 (1):97-109.
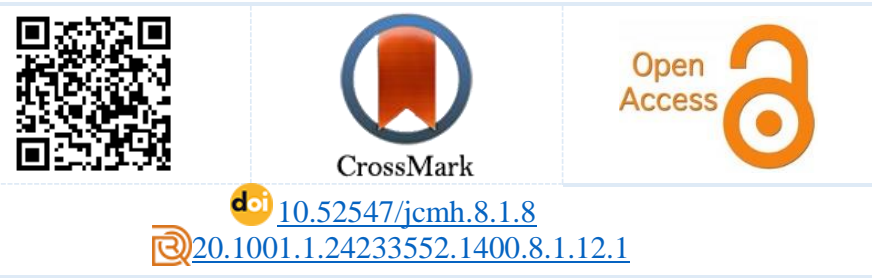

URL: http://childmentalhealth.ir/article-1-1135-en.html

\section{A R T I C L E I N F O}

Keywords:

Systematic

desensitization,

self-regulation,

internet dependence,

students

Received: 28 Jan 2021

Accepted: 18 May 2021

Available: 18 Jun 2021

\section{A B S T R A C T}

Background and Purpose: The extreme use of digital tools is one of the most influential factors in academic achievement. Meanwhile, using the Internet is the most common occupation among students. The present study aimed to determine the effectiveness of systematic desensitization and self-regulation on the students' dependence on the Internet.

Method: The present study was a quasi-experimental design with a pretest-posttest design and a control group. Forty-five students with the highest scores in the Kimberly Young (1995) Internet Addiction Questionnaire were selected by convenient sampling from Rasht city over the academic year 2018-2019, and randomly assigned to two experimental groups and a control group. After 12 sessions of systematic desensitization and self-regulation interventions, the Internet Addiction Questionnaire was administered again. Statistical data were analyzed using univariate analysis of covariance and SPSS-21 statistical software.

Results: The results showed that regular desensitization and self-regulation training was effective on students' dependence to the Internet $(\mathrm{P}<0.01)$. Also, self-regulation had a greater effect on students' Internet dependence than the systematic desensitization $(P<0 / 001)$.

Conclusion: Systematic desensitization with behavioral changes, and self-regulation with cognitive changes, reduce the Internet dependence; therefore, these two educational approaches can be used to reduce students' Internet dependence.

* Corresponding author: Leila Moghtader, Assistant Professor, Assistant Professor, Department of Psychology, Rasht Branch, Islamic Azad University, Rasht, Iran.

E-mail: Moghtaderleula@yahoo.com

Tel: (+98) 133351139

2476-5740/ (C) 2021 The Authors. This is an open access article under the CC BY-NC-ND license

(https://creativecommons.org/licenses/by-nc-nd/4.0/). 


\section{Extended Abstract}

\section{Introduction}

Internet addiction is defined as the overuse of the Internet, which is associated with significant functional impairment, anxiety, depression, and other symptoms of psychiatric pathology (8) and even suicide (9). Adolescents and students are the main users of the Internet. One of the interventions that can affect Internet addiction is systematic desensitization. Regular desensitization is a type of psychological therapy based on behavioral approach and is based on the premise that most abnormal behaviors are acquired, thus we can forget everything we have learned and instead learn more adaptive reactions (14).

The effectiveness of systematic desensitization on Internet addiction has not been directly studied, but Misemi Bonab in a study (16) concluded that desensitization significantly reduces tempting beliefs in addict peoples. Among the factors affecting Internet dependence, self-regulatory psychological structures (18), have a significant effect. Self-regulation means the capacity of the individual to adjust behavior in accordance with the conditions and changes of the external and internal environment (20). May et al. (18) showed that selfcontrol and self-regulation are strongly related to the problems of Internet use in high school adolescents. In a study, Odaki and Click (24) showed that the higher the self-regulation of people, the lower their Internet dependence. Many interventional studies have been conducted on Internet addiction, however no direct studies have used behavioral interventions such as systematic desensitization and cognitive interventions such as self-regulation to reduce Internet addiction. Regarding the increasing number of this type of dependence in students, which can lead to academic failure and reluctance to care their essentials, the present study aimed to determine the effectiveness of systematic desensitization and selfregulation on the students' dependence on the Internet.

\section{Method}

This is a quasi-experimental study with a pretestposttest design and a control group. Among the fifth and sixth grade students of elementary school studying in one of the schools of Rasht city in the academic year 2017-2018, 45 ones were selected by convenient sampling method with the highest scores of Internet dependence, and randomly assigned to two experimental groups and a control group. Inclusion criteria include satisfaction of students and parents to participate in research, obtaining the required cut-off score in the Internet Addiction Questionnaire, no history of serious psychological and psychiatric illnesses, and no use of psychiatric medicines. Exclusion criteria of the research includes no continuous participation in intervention sessions (absence of more than two sessions), or cancel the continuation of the treatment process and participating in the research.

The measurement tool in the study was the Kimberly Young Internet Dependence Questionnaire, which was developed in 1988 (28). Systematic desensitization was based on behavioral approach and taken from the training package of Kazemian et al. (30), and was performed 12 sessions of 45 minutes as group, by the researcher, twice a week. The content of the sessions included 3 sessions of creating Internet hierarchy, 4 sessions of relaxation training and 5 sessions of reciprocal conditioning. Self-regulatory intervention based on cognitive approach and taken from the educational package of Ghareh Aghaji et al. (31), was set and performed in 12 sessions of 45 minutes as a group for students in the experimental group in 12 sessions and 4 steps. The control group did not receive any intervention. Both experimental groups received the relevant interventions simultaneously by two researchers specializing in the relevant fields and in one of the psychology clinics of Rasht city. All three groups answered the Internet Addiction Questionnaire (Iranian version) in the pre-test and posttest stages. Ethical considerations including obtaining written consent from the subjects and keeping personal information confidential and leaving the study if the subjects did not wish to continue the research, were observed. Statistical data were analyzed using univariate analysis of covariance and SPSS-21 statistical software. 


\section{Results}

The descriptive indices of the experimental and control groups in the pre-test and post-test stages are presented in Table 1.

Table 1. Descriptive indices of three groups in the research variable

\begin{tabular}{ccccccc}
\hline \multirow{2}{*}{ variable } & \multirow{2}{*}{ group } & \multicolumn{2}{c}{ pre-test } & \multicolumn{2}{c}{ post-test } \\
\cline { 2 - 6 } & & mean & standard deviation & mean & standard deviation & Shapiro - Wilkes \\
\hline \multirow{2}{*}{$\begin{array}{c}\text { Internet } \\
\text { dependence }\end{array}$} & systematic desensitization & $56 / 53$ & $4 / 12$ & $40 / 73$ & $3 / 63$ & $0 / 95$ \\
& Self-regulation & $45 / 71$ & $3 / 13$ & $36 / 6$ & $5 / 55$ & $0 / 98$ \\
0
\end{tabular}

Analysis of covariance was used to investigate the effect of systematic desensitization and selfregulation on Internet dependence. Therefore, the assumptions of this test which includes the study of normality, regression homogeneity between variables, linear relationship between variables, and homogeneity of variance of variables were examined before performing the analysis report. Table 2 represents the results of univariate analysis of covariance to examine the differences between experimental and control groups in the Internet dependency variable.

Table 2. Results of univariate analysis of covariance to examine the differences between experimental and control groups in Internet dependence

\begin{tabular}{|c|c|c|c|c|c|c|}
\hline Source & Sum of Squares & Degrees of freedom & Mean of Squares & Statistics F & $\bar{p}$ & Impact factor \\
\hline group & $1461 / 8$ & 2 & $730 / 9$ & $26 / 33$ & $0 / 26$ & $0 / 56$ \\
\hline Error & $1137 / 95$ & 41 & $27 / 76$ & & & \\
\hline
\end{tabular}

According to Table 2, the F-statistic is Internet dependence in the post-test (26.33) which is significant at the level of 0.26 . This shows that there is a significant difference between three groups in the degree of Internet dependence. Impact factor of 0.56 also shows that this difference is large in the community. According to this finding, it can be said that systematic desensitization and self-regulation has reduced students' dependence on the Internet. The results of Bonferroni post hoc test were presented in Table 3 to investigate which of the experimental groups had this effect.

Table 3. Pairwise differences of experimental groups in the dependent variable

\begin{tabular}{|c|c|c|c|c|}
\hline variable & Group & difference between means & Standard deviation error & Significance level \\
\hline \multirow{3}{*}{ Internet dependence } & $\begin{array}{c}\text { systematic desensitization - } \\
\text { self-regulation }\end{array}$ & $4 / 13$ & $1 / 42$ & $0 / 001$ \\
\hline & systematic desensitization - control & $-6 / 87$ & $0 / 93$ & $0 / 001$ \\
\hline & $\begin{array}{l}\text { self-regulation- } \\
\text { control }\end{array}$ & -11 & $1 / 08$ & 0/001 \\
\hline
\end{tabular}

The results of Bonferroni test in Table 3 show that in the variable of Internet dependence, the difference between two experimental groups with the control group and with each other is significant $(\mathrm{P}<0.001)$.
This means that both methods (systematic desensitization and self-regulation) have been effective in reducing students' dependence on the Internet. Also, self-regulatory education has been 
significantly more effective in reducing students' dependence on the Internet than the systematic desensitization education.

\section{Conclusion}

The findings of the present study showed that systematic desensitization and self-regulation are effective on students' dependence on the Internet, which is similar with the results of the research by Pour Razavi et al. (25), Misemi Bonab (16), Mei and et all (18). In explaining this finding, it should be noted that self-regulation enables peoples to monitor their behavior and judge their behavior according to some criteria and standards, and then plan and organize their behavior through the rewards, punishments and environmental changes (25). Systematic desensitization can create a kind of mental preoccupation for the Internet addiction and lead to avoidant behaviors, reluctant, and Lack of motivation. During training sessions using problem solving techniques, people who are addicted to the Internet use problem-oriented strategies and logicbased methods instead of emotion-oriented strategies such as using the Internet in solving everyday problems. So far, no study has been done on these two comparisons in the treatment of Internet addiction. However, it seems that the reason for the greater effectiveness of self-regulatory education than systematic desensitization was the effectiveness on students' cognition, which had a deeper effect on the change in behavior created in systematic desensitization education.

The present study was associated with limitations such as lack of control over the socio-economic status of subjects, lack of random sampling, and the use of self-report tools in assessing Internet dependence. Therefore, it is suggested that they be considered in future similar studies. According to the research findings, it is suggested to held courses on systematic desensitization and self-regulation training for students who are addicted to the Internet, and even prepare and explain the necessary exercises in the form of brochures and allow them to continue practicing outside of training sessions. According to the results of this study, it is suggested that two methods of systematic desensitization and selfregulation be used simultaneously to reduce students' dependence on the Internet.

\section{Ethical Considerations}

Compliance with ethical guidelines: This article is taken from the research plan approved by the Guilan Education Organization with the number 12016/16/17 dated 2019.7.9. The other ethical considerations such as complete satisfaction of the sample, and observance of the principle of confidentiality of information have also been considered in this study.

Funding: This study was conducted with the national support of the Education Organization of Guilan Province.

Authors' contribution: The first author of the article, as the main originator of the research: the second author, as the executor of the project: and the third author, as the executor and translator of the research have played a role in this study.

Conflict of interest: According to the authors, there was no conflict of interest for any of the authors in this study.

Acknowledgments: The authors of the article consider it necessary to appreciate the cooperation of the Education Organization of Guilan Province and all participants in the research and all those who helped in the implementation of this research. 


\section{اثربخشى حساسيتزدايى منظم و خودتنظيمى بر وابستغى داش آموزان به اينترنت}

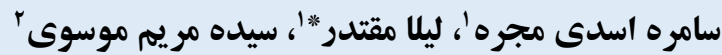

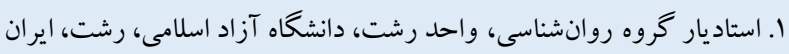

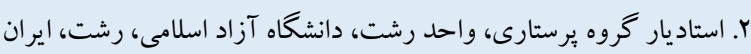

\section{جكيده}

زمينه و هدف: يكى از عوامل بيرونى تأثير گذار بر افت تحصيلى، استفاده افراطى از ابزارهاى ديجيتالى است. در اين ميان استفاده از اينترنت

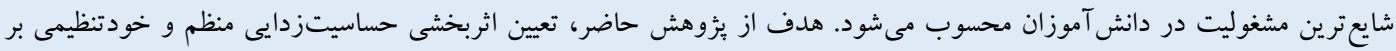
وابستكى دانش آموزان به اينترنت بود.

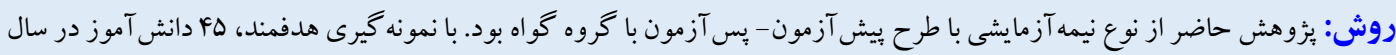

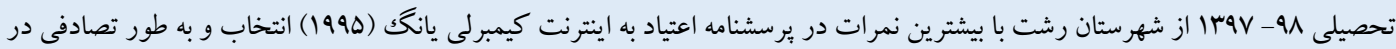

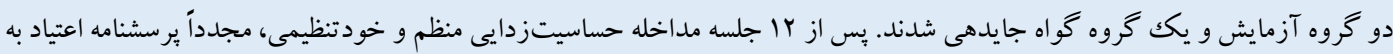

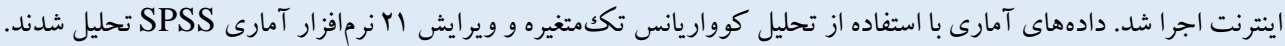
يافتها: نتايج نشان داد آموزش حساسيتزدايى منظم و خودتنظيمى بر وابستكى دانش آموزان به اينترنت مؤثر بوده است. همجنين

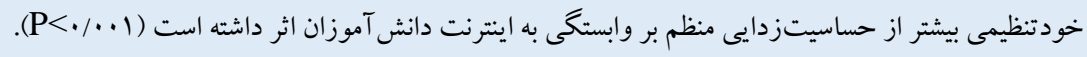

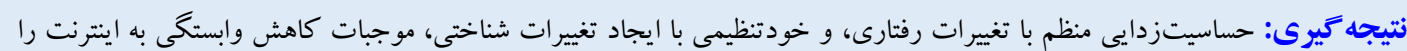
فراهم مى آورد؛ بنابر اين مى توان از آموزش حساسيتزدايى منظم و خودتنظيمى در كاهش وابستخى به اينترنت دانش آموزان بهره برد.
مشخصات مقاله

كليدوازهها:

حساسيتزدايى منظم،

خود تنظيمى، وابستخى به اينترنت، دانش آموزان

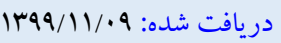

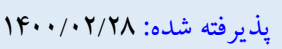

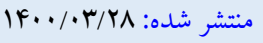

* نويسنده مسئول: ليلا مقتدر، استاديار گروه روانشناسى، واحد رشت، دانشگاه آزاد اسلامى، رشت، ايران. رايانامه: Moghtaderleula@yahoo.com 
خانو ادهها مىشود كه از آن ميان مىتوان به كاهش ارتباطات ميانفردى

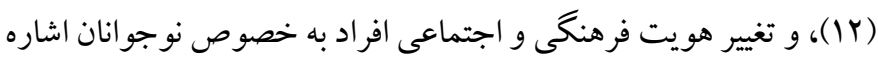

كرد (ir)

يكى از مداخلاتى كه مىتواند اعتياد اينترنتى را تحت تأثير قرار دهد،

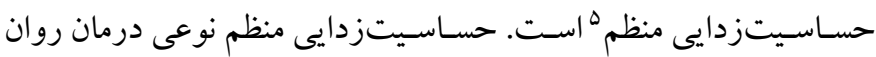

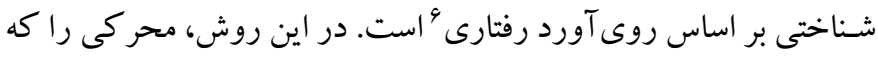

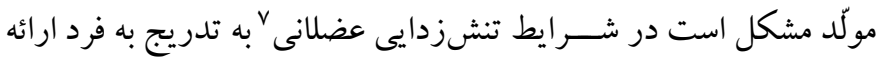

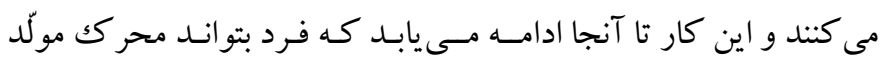

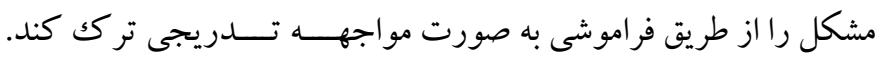

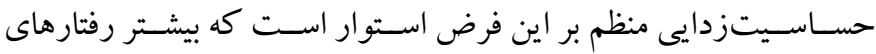

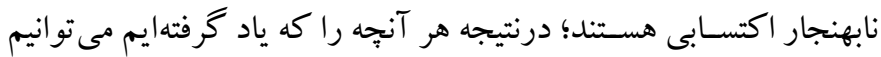
از ياد ببريم و به جاى آن واكنشهاى سازش يافتهترى را ياد بكيريم (F (I).

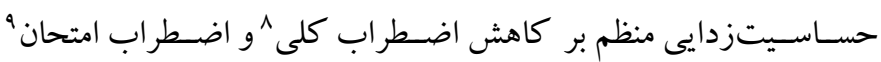

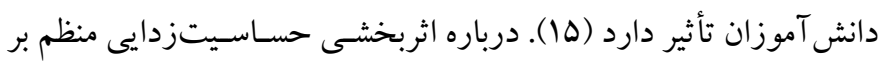
اعتياد به اينترنت، بزوهش هاى محدودى انجام شـده اسـت. ميسمى بناب

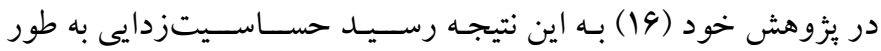

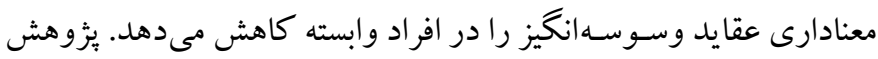

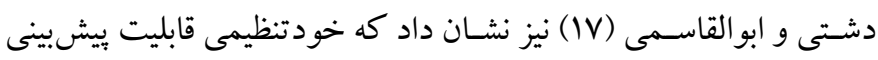
اعتياد به شبكههاى اجتماعى را دارا است.

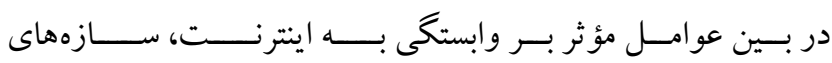

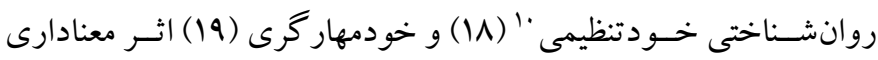

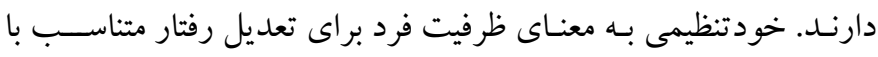

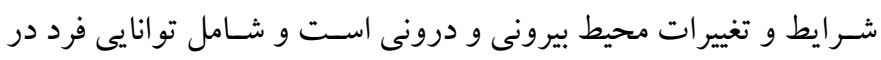

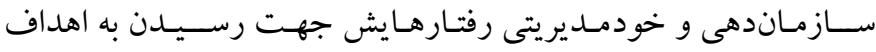

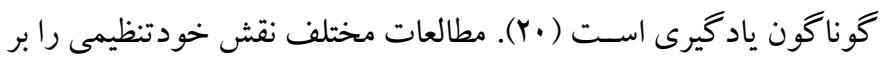

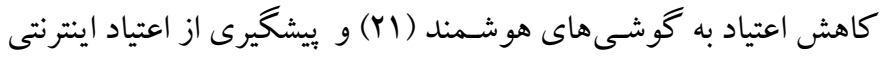

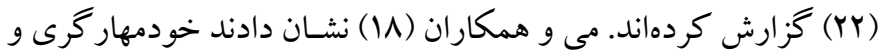
خودتنظيمى با مشكلات استفاده از اينترنت در نوجوانان دبيرستانى رابطه

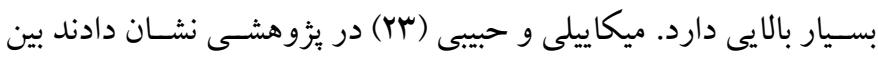

\section{Behavioral Approach}

7. Muscle Relaxation

8. Generalized Anxiety

9. Exam Anxiety

10. Self-Regulating مقلdo

با محبوبيت سريع تلفن هاى هو شمند، دسترسى به اينترنت' به طور فزاينده -

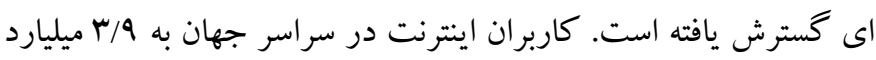

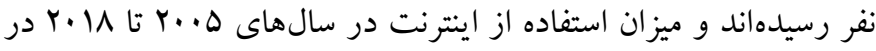

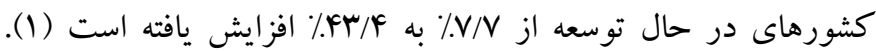

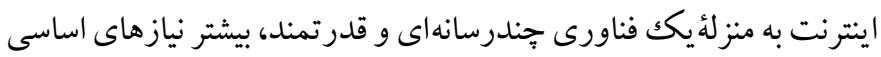

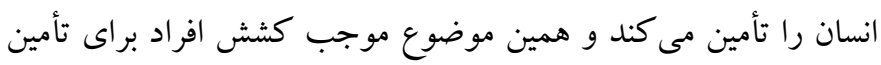

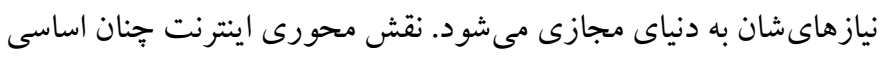

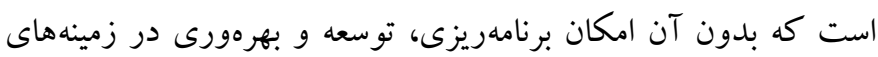
فرهنكى، اجتماعى، اقتصادى و علمى در آينده وجود نخو اهد داشت (Y).

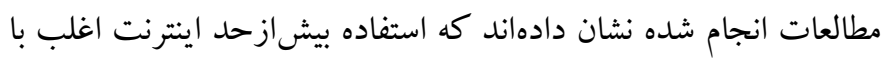
شرايط نامطلوب سلامتى از جمله يريشانى جسمانى و هيجانى (مانند

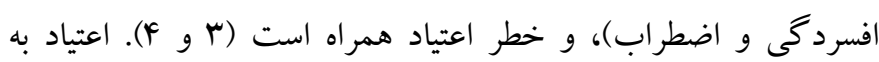

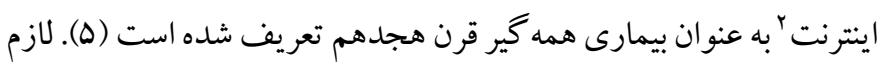

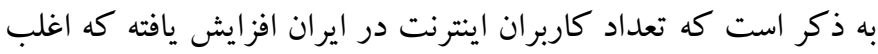
آنها را دانش آموزان تشكيل مىدهند (9). بر اساس مطالعه انجام شده

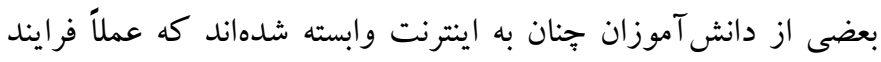

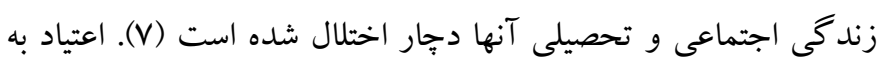

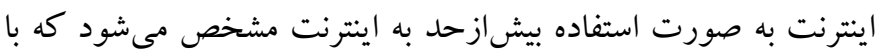

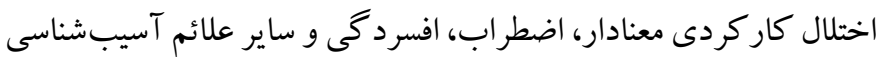
روانى (N) و حتى خو دكشى (9) همر اه است. وابستكى به اينترنت به دليل

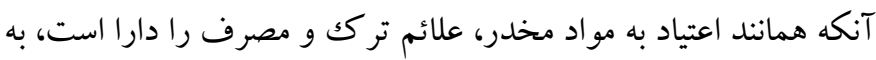

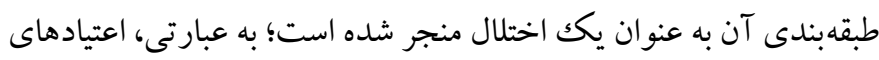

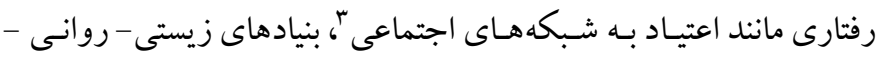

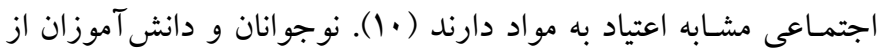

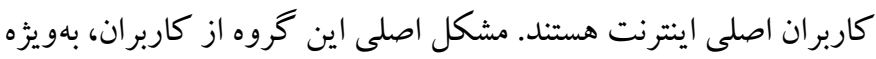

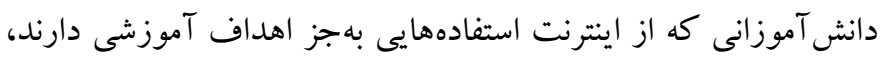

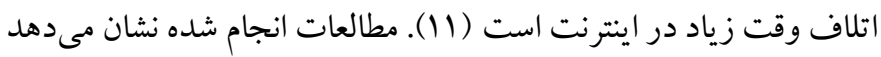

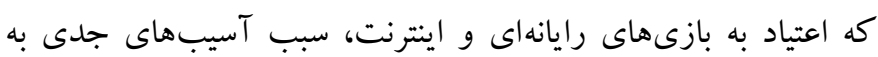

1.Internet

2.Internet addiction

3.Social Networks

4.Interpersonal communication

5.Regular Sensitization 
دانش آمــوزان يايه هاى ينجم و ششم مقطع ابتدايى شــاغل بـهـ تحصيـل

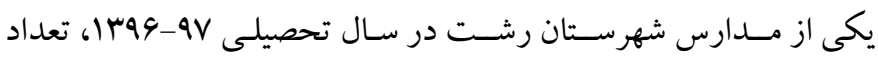

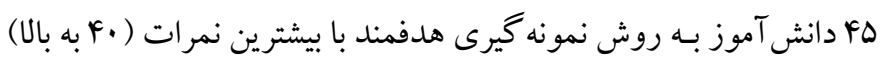

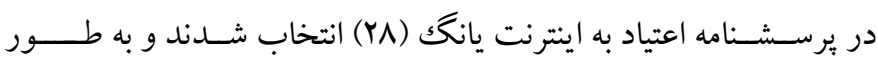
تصادفى و مسـاوى در ץ گ خروه آزمايش و يكك گروه گكواه (هر كدام

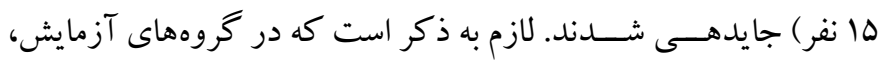

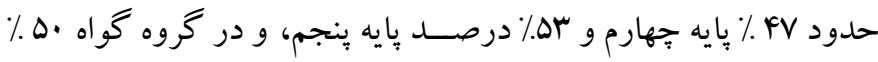

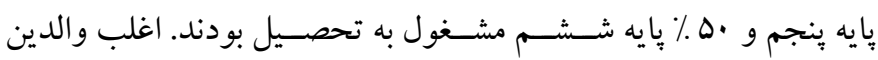

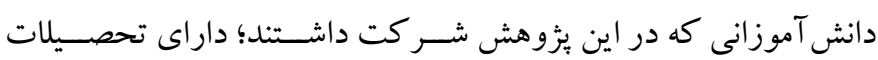
ليسانس و يا بالاتر بودند ( •9.").

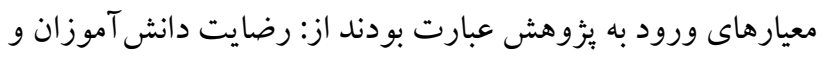

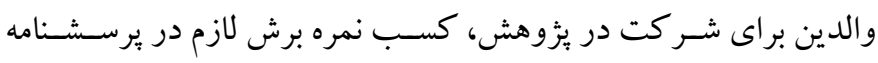

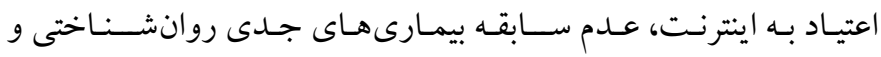

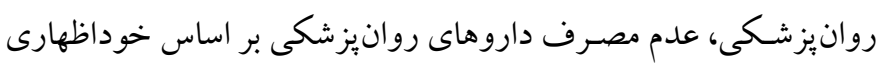

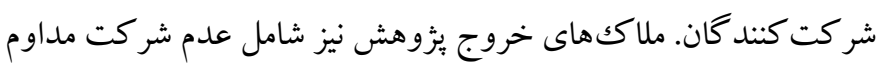
در جلسـات مداخله (غيبت بيش از دو جلسـه)، يا انصـراف از ادامه روند درمان و مشاركت در بثوهش بود. ب) (بزار ا ـ برسشنامه وابستكى به اينترنت يانخك ': اين برسشنامه توسط كيمبرلى

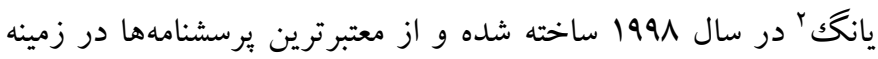

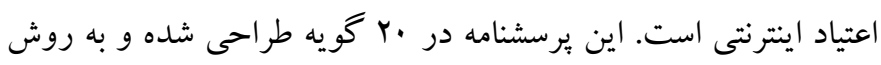

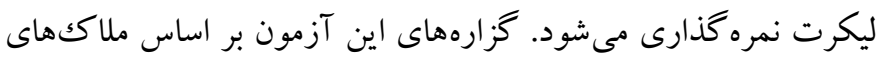
ويرايش جهارم راهنماى تشخيصى و آمارى اختلالات روانى براى تشخيص اعتيادهاى رفتارى بطر احى شده است كه جنبه هاى مختلف اعتياد

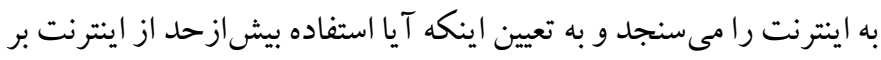

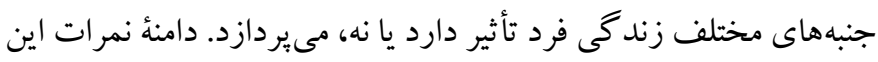

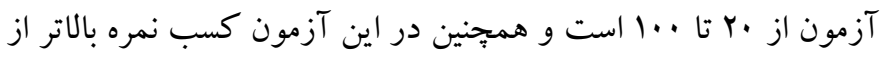

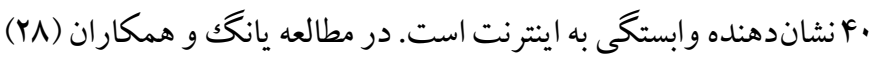

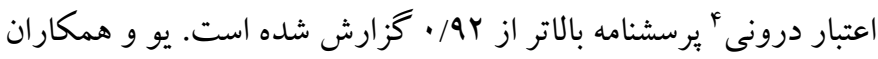

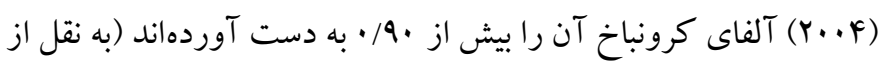

3. Behavioral Addiction

4. Inter Reliability
اعتياد به اينترنت وخود تنظيمى هيجانى، حسـاسيت به طرد و خودافشايى برخط با ميانجيخرى اضطر اب اجتماعى در دانشجويان رابطه وجود دارد.

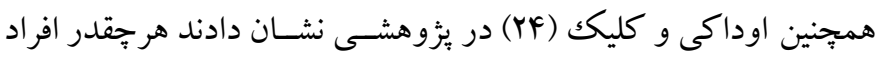

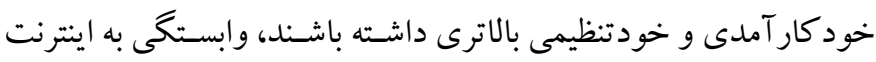

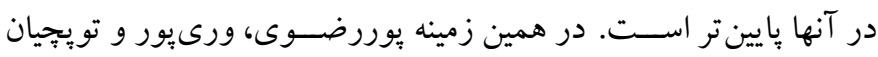
(YD) نقش خودتنظيمى و خودمهـار گرى راد در اعتيـاد بـه تلفن، معنـادار

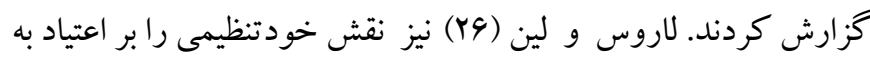

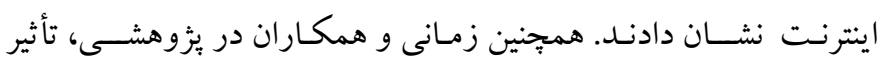

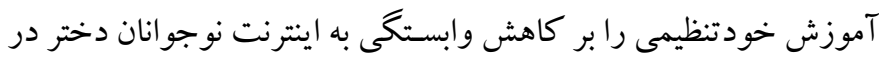

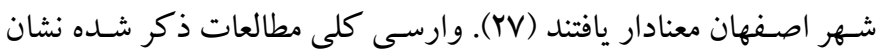

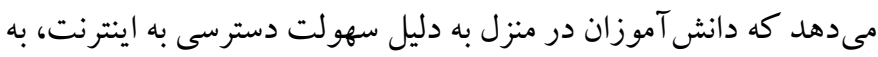

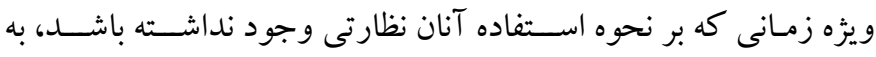

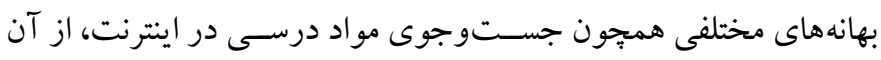

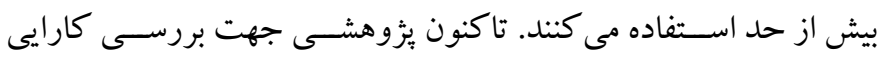
درمان حســاسـيتزدايى و خودتنظيمى بر اعتياد اينترنتى دانش آموزان

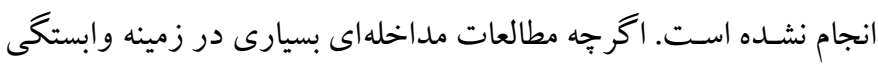

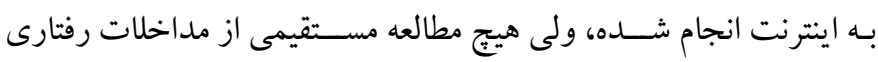

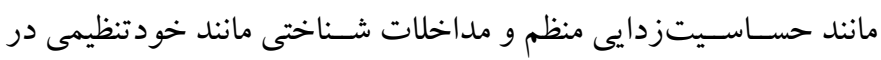

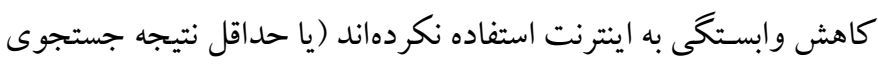

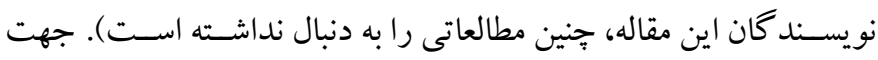

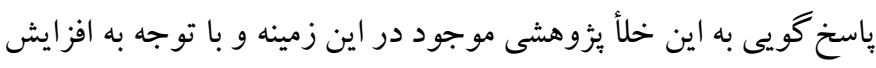

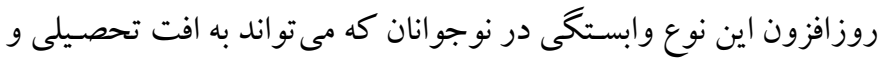

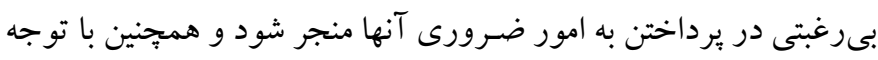

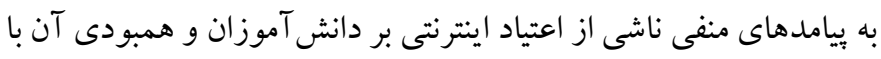

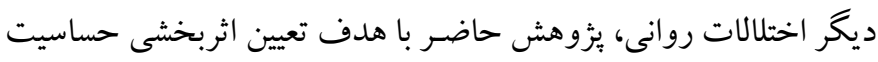

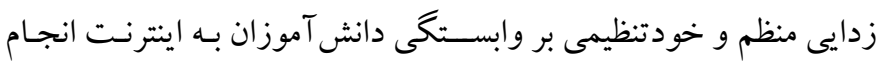

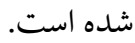

روش

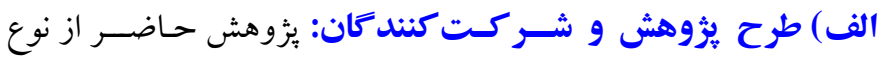

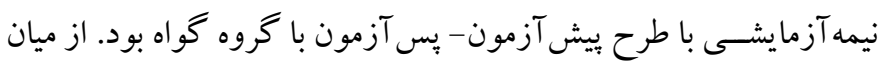

1. Internet Addiction Test (IAT)

2. Kimberly Young 
مـــوردى از علائم وابستخى خود رابرحسب درجه شدت تنش از خفيف تا شديد تهيـه كرد. در مرحله دوم، ضسمن آموزش تن آرامى، هر يكك از

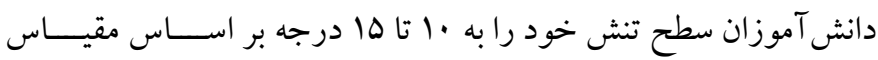
صـفر تـا صــد خواهند رساند (جلسات جهارم تا هفتم). در مرحله سوم، ابتدا هر يكك از افراد آرامش را تجربه كرده و ســــــس از آنها خواسـته خو اهد شد تا بــه ترتيـب، جهـار رويـداد نخست را تجسم كنند و در طى جلســات بعـد اين كـار ادامـه يـافـت تا تمام رويدادها به تجســم درآيد (جلسات هشـــتم تا يازدهم). در جلسه آخر (دوازدهـــم) مجدداً تمـــام رويدادهاى به تجسم در آمده در پايان روش درمــانى تمرين شد و سبس از همــهُ افــراد خواسـته شـــ در جلسـهـ يـس آزمـون شركت كنتد. در جدول ا، خلاصـه محتواى جلسـات حسـايتزدايى منظم كزارش شــده
9Y). خصوصيات روانسنجى يرسشنامه اعتياد به اينترنت يانگك توسط علوى و همكاران مورد بررسى قرار گرفت كه نتايج با استفاده از روش-

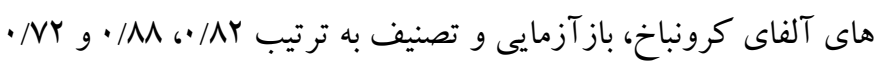
محاسبه شد (Y9). همجينين، در ايران، روايى اين ثيرسشنامه نيز به روش محتوايى و صورى بررسى و تأييد شده است. در يزوهش حاضر، همسانى درونى اين ثيرسشنامه با روش آلفاى كرونباخ شه/ • به دست آمد. ج) برنامه مداخلهاى: حساسيتزدايى منظم بر اساس روى آورد رفتارى

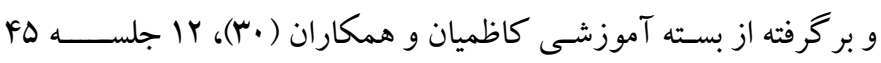
دقيقهاى بـه صسورت كروهـى توسط يثزوهشخر، و هفتهاى ب جلسه اجرا

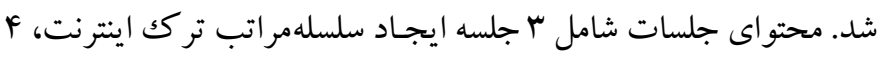
جلسه آموزش تن آرامى، و ه جلسه شرطىسازى تقــابلى بود. در مرحلـه

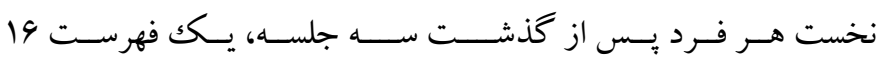

\begin{tabular}{|c|c|}
\hline محتواى جلسات & حلسات \\
\hline معارفه، آشنايى با يكديخر، توضيح درباره اهداف و محتواى برنامه، ايجاد فهرست سلسله مراتبى علائم وابستخى به ايترنت، بيش آزمون & يكم \\
\hline آموزش راهبردهاى افزايش رفتارهاى مثبت جايخزين رفتارهاى مخرب & دوم \\
\hline آموزش راهبردهايى براى غلبه بر اضطراب ناشى از ترك اينترنت & 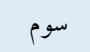 \\
\hline آرامش آموزى با تنفس، نمره گذارى تنش & جهارم \\
\hline آرامش آموزى با تنشزدايى If عضلانى & ينجم \\
\hline آرامش آموزى با تنشزدايى 9 عضلانى & ششم \\
\hline آرامش آموزى با تنشزدايى ب عضلانى & هi \\
\hline مديريت رفتار ناكار آمد & هشتم \\
\hline تجسمسازى با تكنيك تصور رويدادهاى يرخطر درون خانه & نهم \\
\hline تجسم سازى با تكنيك تصور رويدادهاى برخطر بيرون از خانه & دهم \\
\hline تقويت رفتارهاى اصلاح شده & 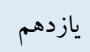 \\
\hline شركت در بِ آزمون & 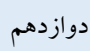 \\
\hline
\end{tabular}

نشـانه هاى داخلى و خارجى از طريق خود آكاهى بيشـتر، داشـتن توانايى خوديايشــى، ضــرورى مى شـــود تا باعث هدايت راهبردهاى مداخله به صـورت سـريع تر، بهتر و متناسـبـتر شـود. خوديايشسى توجه ماهر انه و عمدى به برخى از جنبه هاى رفتارى اسـت؛ مثل ثبت تكرار رفتارها، ثبت شـدت رفتارها، و ثبت دورهاى رفتارها.كام سوم، خودارزشيابى، كشف، و مقـايســه اختلـاف بين رفتارهاى موجود و رفتارهاى ايده آل برحسـبـ اهداف تعيين شـده اسـت.كام جهارم، خودتقويتى: اين مرحله با توجه به افر اد، و موقعيـت هـاى متفـاوت در افراد كروه نمونـه و بســــى به نتيجه
مداخله خود تنظيمى بر اسـاس روى آورد شـناختى و بر كر فته از بسـته

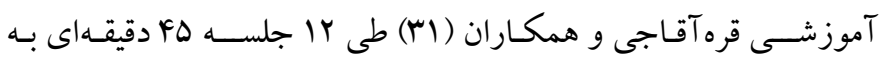

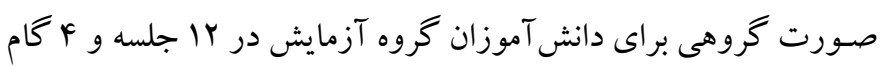
تنظيم و اجرا شـد. كام نخستـ، تعبين /هداف: تعيين اهداف در واقع بيدا كردن اصــولى براى مشــخص كردن ميز ان اختلاف بين وضــع موجود و وضـع ايدهآل اسـت. اهداف بايد داراى خصـوصسياتى باشند كه اهم آنها عبـارتانـد از: ويز كى خـاص، نزديكك بودن هدف، درجه ســتى. كام دوم، خوديا يشى: هنگامى كه هدف تعيين شد، به علت توجه به اشارات و 
و شـشـم تعداد ه\& دانش آموز با بيشـترين وابستكى به اينترنت با توجه به

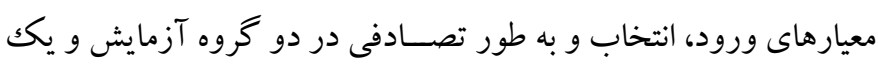

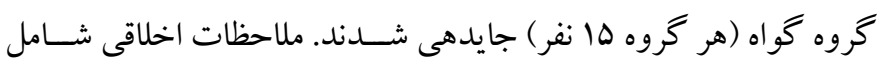

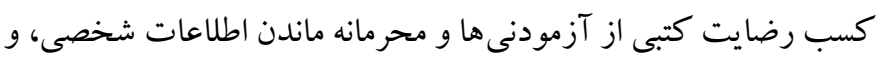

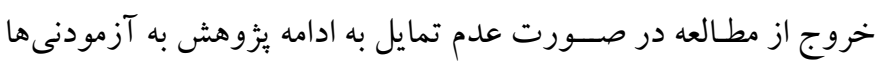

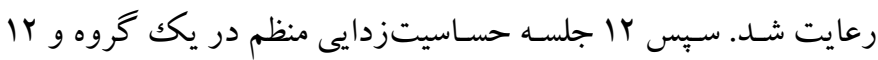
جلسـه خودتنظيمى در گروه ديخر آزمايش، در يكى از كلينيككهـاى روانشـناسى شـهرستان رشت توسط دو متخصص روانشناسى اجرا شد.

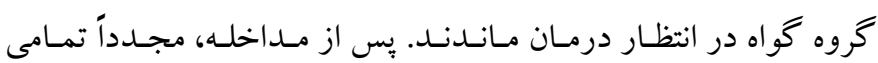
يرسـشـنامهها توسـط هر دو گروه آزمايش و گُواه تكميل و تحليل انجام شـد. جهت تحليل از روشهاى توصسيفى ميانخين و انحر اف اسـتاندارد و روش اسـتنباطى تحليل كوواريانس تككمتغيره يككراهه و آزمون تعقيبى تُوني بونفرونى با ويرايش ابr نرمافزار SPSS استفاده شد.

\section{يافته ها}

شاخص هاى براكندگى و مركزى گروههاى آزمايش و گواه در مراحل

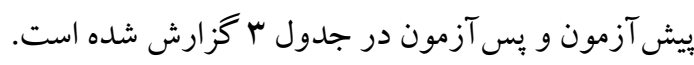

ارزشــــابى دارد. مقــايسـهـ و ســنجش هـاى اجتماعى مى تواند بر فر ايند خودتقويتى اثر بخذارد. در جدول ب، خلاصسه جلسـات خود تنظيمى ارائه شده است.

جدول r: خلاصه جلسات خودتنظيمى

\begin{tabular}{|c|c|}
\hline معارفه، تبيين اهداف جلسات و بيش آزمون & 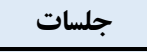 \\
\hline آشنايى با گروه و معارفه، تشريح اهداف و تكميل بيش آزمون & 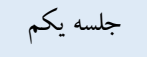 \\
\hline خوديايشى، خودمهار گرى، ثبت روزانه فعاليتها & 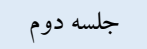 \\
\hline تمرين تكنيك توقف فكر با تمثيل ابر گذرنده & 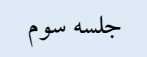 \\
\hline تمرين تكنيك توقف فكر با تمثيل جراغ راهنمايى & جلسه جهارم \\
\hline آموزش تفكيك انگيزش درونى و بيرونى & جلسه ينجم \\
\hline آموزش خودتنظيمى و ييامدهاى كو تاممدت و بلندمدت & جلسه ششم \\
\hline آموزش برنامهريزى براى دستيابى به اهداف & جلسه هفتم \\
\hline آشنايى با تحريفهاى شناختى، اصلاح نخرش همه يا هيج & جلسه هشتم \\
\hline 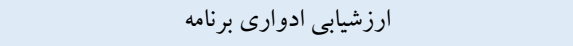 & 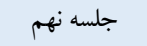 \\
\hline اولويت گذارى، مديريت تنيدگى & جلسه دهم \\
\hline خود تقويتى، خود تنبيهى و دريافت پِخوراند & جلسه يازدهم \\
\hline يس آزمون & 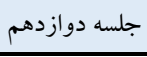 \\
\hline
\end{tabular}

د) روش اجر ا: بِ از اخـــ مجوزهـاى للازم جهت يُوهش از ســازمان

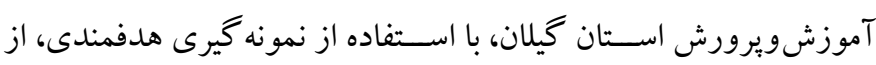

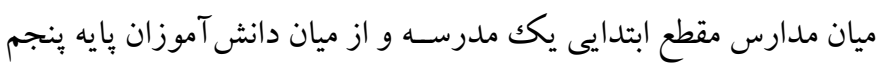

جدول "ّ: شاخص هاى مركزى و براكند

\begin{tabular}{|c|c|c|c|c|c|c|}
\hline \multicolumn{3}{|c|}{ يَ پسآزمون } & \multicolumn{2}{|c|}{ بيش آزمون } & \multirow{2}{*}{ كروه } & \multirow{2}{*}{ متغير } \\
\hline شايِيرو - ويلكز & انحر اف استاندارد & ميانغين & انحر اف استاندارد & ميانغين & & \\
\hline.$/ 90$ & $r / 9 \mu$ & $r \cdot / N r$ & $F / I r$ & $k q / \Delta r$ & حساسيتزدايى منظم & \\
\hline$\cdot / 91$ & $\Delta / \Delta \Delta$ & re/9 & r/M & $F \Delta / V I$ & خود تنظيمى & وابستكى به اينترنت \\
\hline.$/ 99$ & $9 / 1$. & FV/G & $f / F 1$ & $F G / Y F$ & كواه & \\
\hline
\end{tabular}

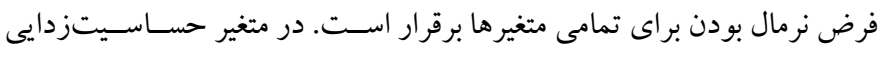

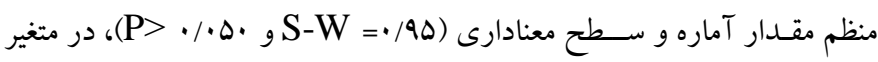

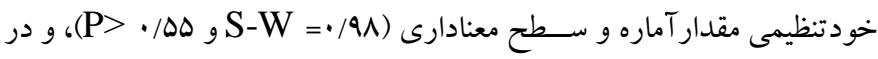

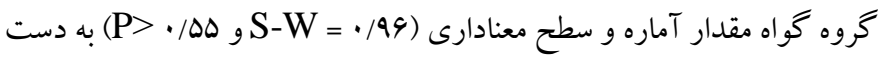
آمد. نتايج آزمون لوين براى بررسسى همخنى واريانس متغير وابسته در كروهها

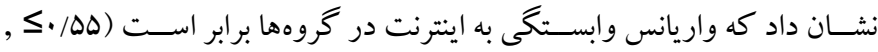
F=1/VP نكرده و در جنين شـرايطى فرض همكنى رگرسيون بين متغيرها نيز وجود دارد. از سـويى ديخر نتايج بررسى همبستـى بين بيش آزمون و بس آزمون نشان داد
بر اسـاس نتايج جدول س در متغير وابستخى به اينترنت، بررسى ميانگين سه

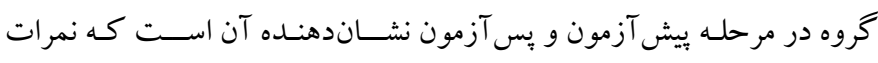
يس آزمون شـ كت كنند كان در گرووه آزمايش افزايش داشته است. للازم به ذكر

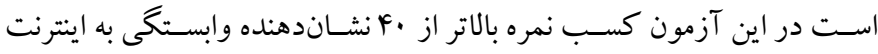
اسـت. براى بررسى تأثير حسـاسـيتزدايى منظم و خود تنظيمى بر وابستخى به اينترنت از آزمون تحليل كوواريانس تككمتغيره يككراهه استفاده شد؛ بنابراين، قبل از انجام گزارش تحليل، ابتدا بيش فرض هاى اين آزمون كه شـامل بررسى نرمال بودن، همكنى ركرسـيون بين متغيرها، ارتباط خطى بين متغيرها، يكسـانى واريانس متغيرها اسـت، مورد بررسى قرار گرفت. آزمون شاييروويلكز نشان داد 
توجه به برقرارى مفروضسهاى آمارى استفاده از تحليل كوواريانس مجاز است.

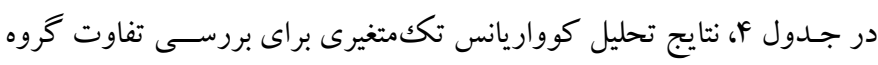

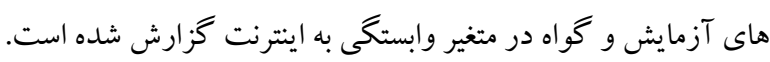

مقدار همبستخى بين بيش آزمون و پِ آزمون وابستخى به اينترنت از نظر آمارى

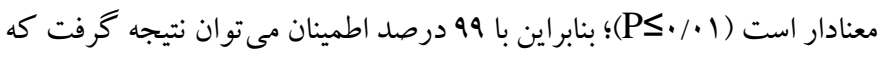

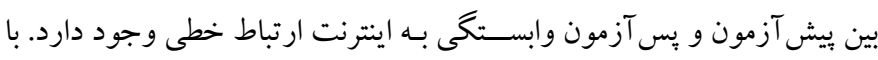

\section{جدول ع: نتايج تحليل كواريانس تكمتغيرى براى بررسى تفاوت كروههاى آزمايش و كواه در وابستكى به اينترنت}

\begin{tabular}{|c|c|c|c|c|c|c|}
\hline اندازه اثر & $\mathbf{p}$ & F آماره F & ميانكين مجذورات & درجه آزادى & مجموع مجذورات & منبع \\
\hline \multirow[t]{2}{*}{$\cdot / \Delta 9$} & $8 / 49$ & $r 9 / \pi r$ & $v r \cdot / 9$ & $r$ & $1491 / 1$ & كروه \\
\hline & & & TV/VY & i) & $\| T V / a d$ & خطط \\
\hline
\end{tabular}

كفت كه حسـاســيتزدايى منظم و خودتنظيمى موجب كاهش وابسـتخى به

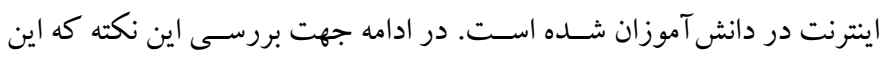

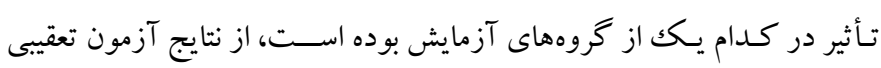
بونفرونى در جدول ها استفاده شده است.

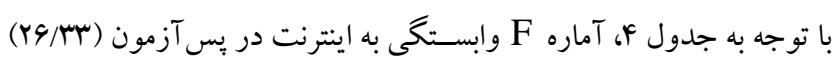

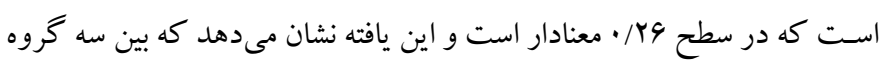

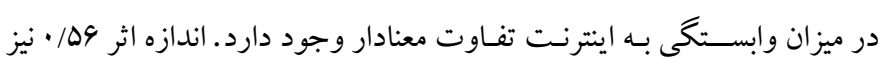

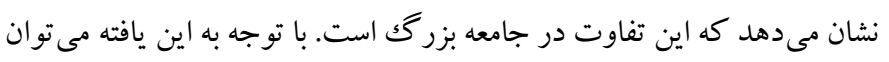

\section{جدول 0: بررسى تفاوتهاى دو به دو در كروههاى آزمايش در متغير وابسته}

\begin{tabular}{|c|c|c|c|c|}
\hline سطح معنىدارى & خطاى انحر اف معيار & تفاوت ميانكينها & كروه & متغير \\
\hline.$/ \cdot 1$ & $1 / 4 r$ & $f / I r$ & حساسيتزدايى منظم - خودتنظيمى & وابستخى به اينترنت \\
\hline.$/ \cdot 1$ & $\cdot / 94$ & $-9 / \mathrm{NV}$ & حساسيتزدايى منظم - گواه & \\
\hline.$/ \cdot 1$ & $1 / \cdot 1$ & -11 & خودتنظيمى - كو اه & \\
\hline
\end{tabular}

توجه به معيارها و استانداردهايى كه دارد در مورد رفتار خود قضساوت

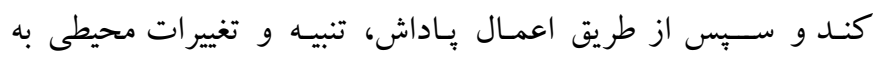
برنامهريزى و سـازماندهى رفتار خود بيردازد. همجنين، خودتنظيمى تلاش فرد جهت رسـيدن به هدف از طريق تحمل بيامدهاى منفى رئى

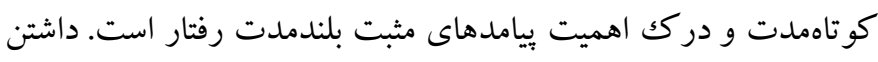
مهارت ناكافى خودتنظيمى درباره اسـتفاده از اينترنت به اعتياد منجر مىشود (YD). افرادى كه از قدرت خودتنظيمى و به عبارتى تنظيم هيجان

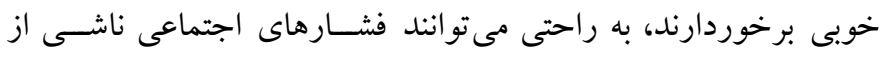

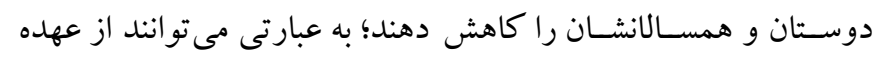

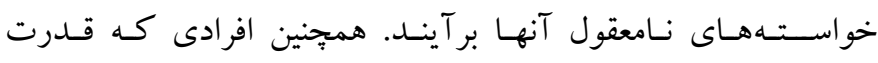

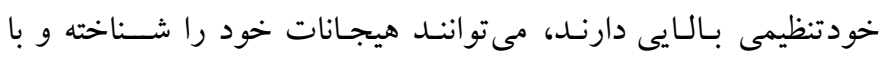

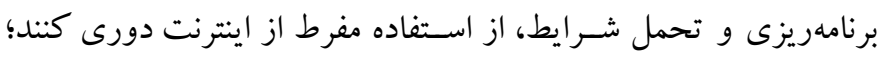

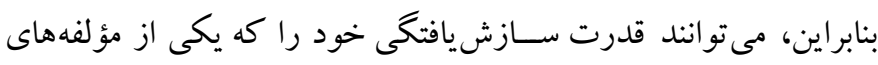
كليدى خودتنظيمى است، افزايش دهند. (YF). تمامى مقوله هاى ياد شده

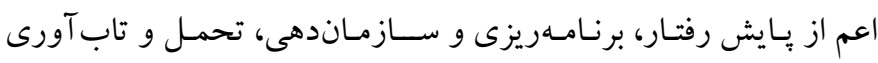

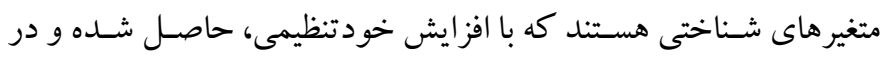

نتايج آزمون بونفرونى در جدول هـ نشـان مىدهد كه در متغير وابسـتخى به

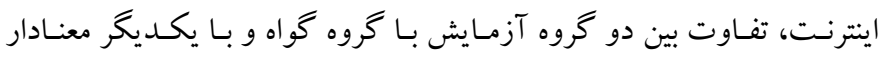

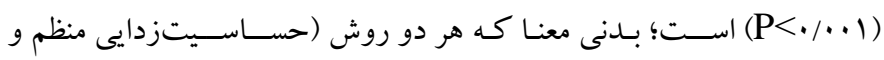

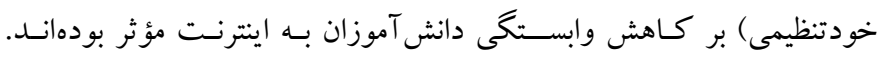

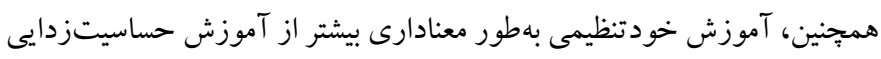

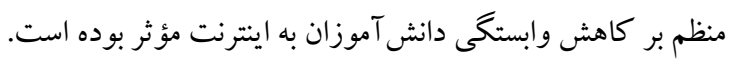

\section{بحث و نتيجه كيرى}

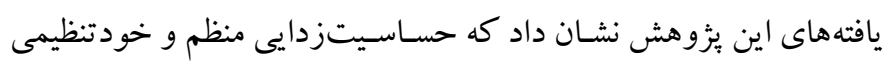

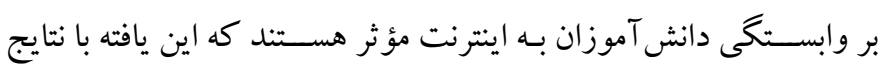

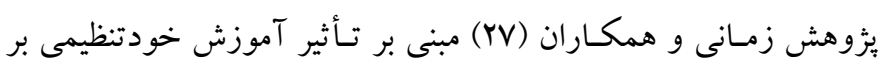

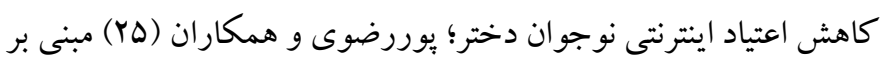

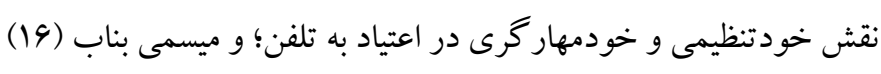

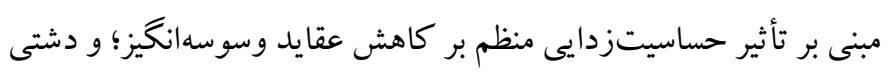

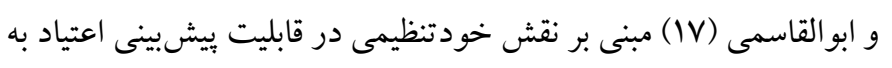

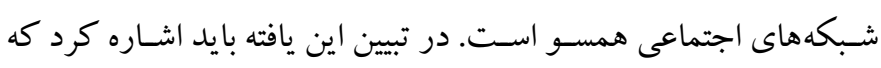

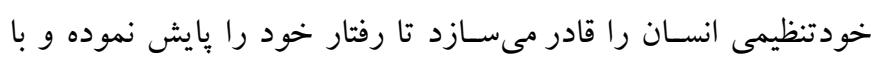




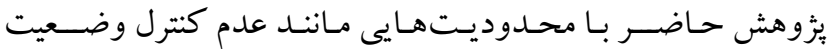

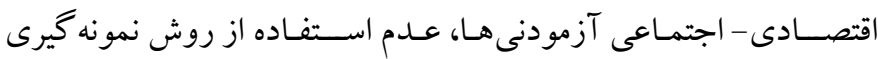

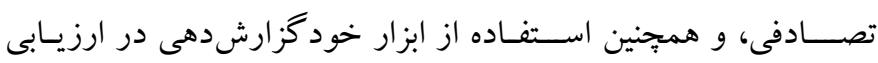

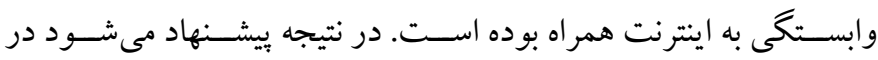

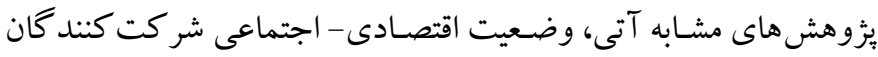

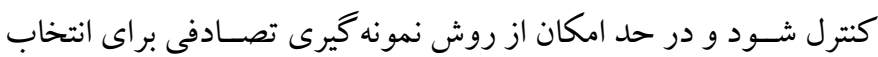

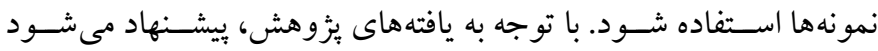

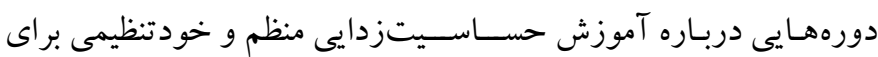

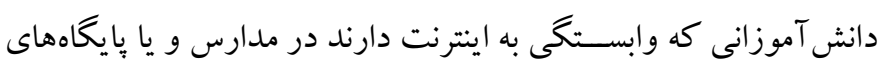

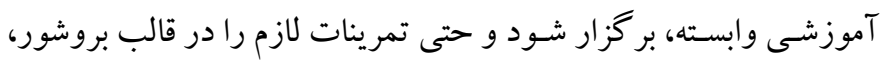
تهيه و توضسيح داده و در اختيار آنها قرار داده شـود تا خارج از جلســات آموزشـى، تمرينات را ادامه دهند. بر اسـاس نتايج اين مطالعه، بيشـــهاد مىشـود كه دو شيوه حساسيتزدايى منظم وخود تنظيمى به طور همزمان در كاهش وابستخى دانش آموزان به اينترنت مورد استفاده قرار گيرد.

\section{ملاحظات اخلاقى} ييروى از اصول اخلاق ئوهش: اين مقاله بركرفنه از طرح يُوهشى مصوب سازمان

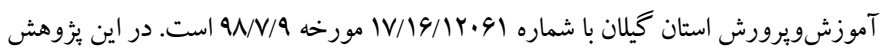

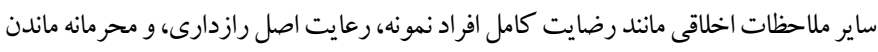
اطلاعات نيز در نظر كرفته شده است. حامى مالى: اين مطالعه با حمايت ملى سازمان آموزشويرورش است استان كيلان انجام شده نقش هر يك از نويسندكان: نويسنده نخست مقاله، به عنوان مجرى طرح و ايدهيرداز

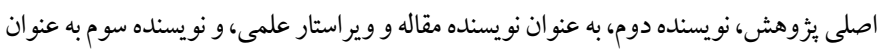
اجرا كننده در اين مطالعه نقش داشتهاند. تضاد منافع: بر اساس اعلام نو يسند كان، در اين مطالعه تضاد منافع براى هيج كدان كدام از نويسند كان وجود نداشته است.

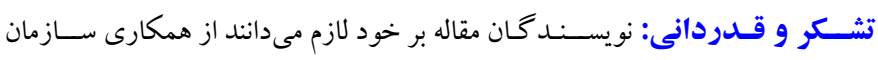

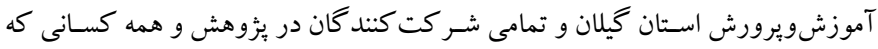
در اجراى اين يزوهش يارى كردند، تقدير و قدردانى كنند.

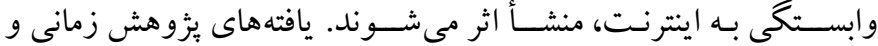
همكاران (YV) نيز نشـان داد آموزش خود دتنظيمى بـا تـأثير بر مؤلفههاى

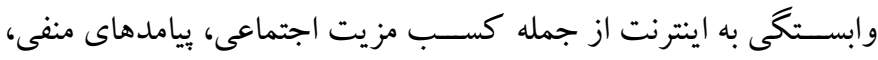

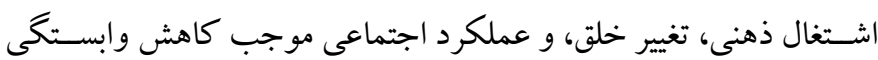
مى شو د. از طرفى حسـاسـيتز دايى منظم مى تواند نوعى مشـغوليت ذهنى براى فرد وابسـتـهـ بـه اينترنـت ايجـاد كرده و رفتـارهـاى اجتنابى و بى ميلى و

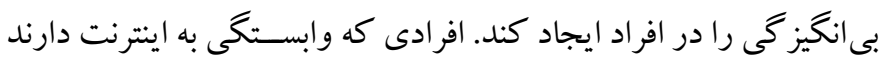

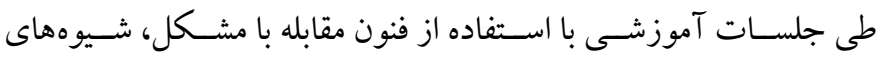
مســـلهدمار و مبتنى بر منطق را جايكزين راهبردهاى هيجانمحور از قبيل

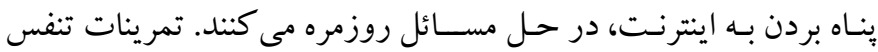

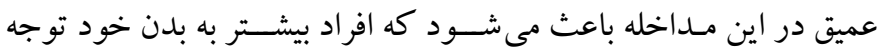
كرده و مشــله ذهنى كمترى با اينترنت و اسـتفاده از آن داشــته باشـــند.

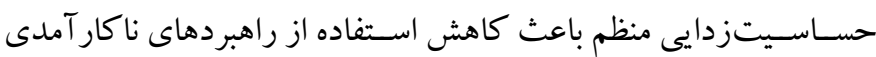

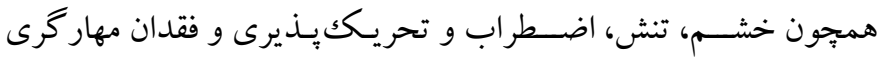

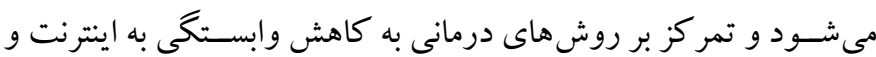
ييامدهاى منفى ناشى از آن منجر مى شود.

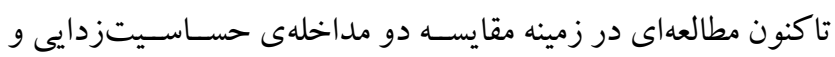

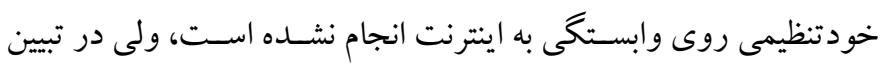

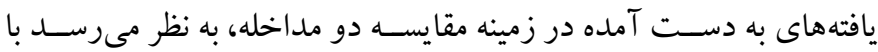
اصسلاحات رفتارى در جلسات حساسيتزدايى، فرايندهاى شرطى سازى و خاموشى، موجب كاهش وابستخى مى شود. از سويى تغييرات شناختى در

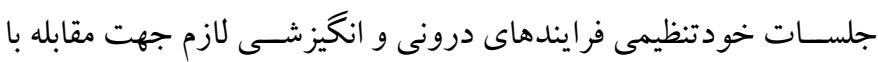

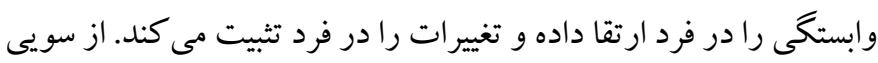

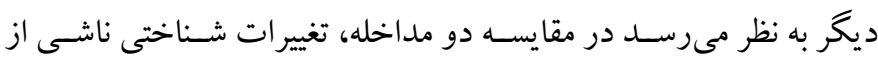
خودتنظيمى، تأثيرات ماندكارترى بر كاهش اعتياد به اينترنت در مقايسـه

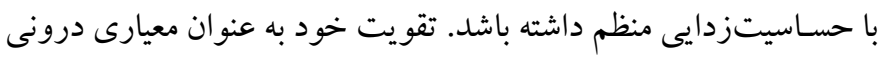

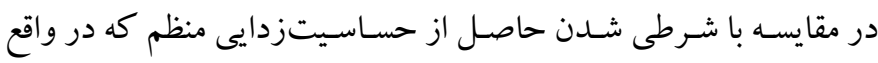

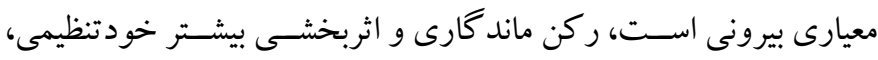

$$
\text { نسبت به حساسيتزدايى است. }
$$




\section{References}

1. Hussain Z, Pontes HM. Personality, internet addiction, and other technological addictions: An update of the research literature. In Multifaceted Approach to Digital Addiction and Its Treatment; IGI Global. 2019; 46-72. [Persian]. [Link]

2. Awasthi P. Role of Internet Addiction in Mental Health Problems of College Students. Psychol Behav Sci Int J. 2017; 2(4): 555591. [Link]

3. Dong H, Yang F, Lu X, Hao W. Internet Addiction and related psychological factors among children and adolescents in China during the coronavirus disease 2019 (COVID-19) epidemic. Front Psychiatry. 2020; 11. [Link]

4. Islam S, Sujan SH, Tasnim R, Ferdous MF, Masud JHB, et al... . Problematic internet use among young and adult population in Bangladesh: correlates with lifestyle and online activities during the COVID-19 pandemic. Addict. Behav. Rep. 2020; 12. [Link]

5. Christakis DA. Internet addiction: a $21^{\text {st }}$ century epidemic. BMC Med. 2010; 1(98): 1-3. [Link]

6. Zarbakhsh Bahri M, Rashedi V, Khademi M. Loneliness and Internet addiction in students. J Health Prom Manag. 2013; 2(1): 32-38. [Persian]. Doi: http://jhpm.ir/article-1-75-en.html. [Link]

7. Mahapatra A, Sharma P. Association of Internet addiction and alexithymia - A scoping review. Addict Behav. 2018; 81: 175-182. [Link]

8. Dresp B. Internet Addiction Disorder (IAD). Ency, Section Psy and Ment Health Stud. 2020: 2-5. Doi: https://hal.archives-ouvertes.fr/hal-02615330. [Link]

9. Su W, Han X, Jin C, et al. Are males more likely to be addicted to the internet than females? Ameta-analysis Involving 34 Global Jurisdictions. Comput Hum Behav. 2019; 99: 86-100. [Link]

10. Jorgenson AG, Hsiao RC-J, Yen C-F. Internet Addiction and Other Behavioral Addictions. Child and Adolescent Psy Clin of North America. 2016; 25(3): 509-520. [Link]

11. Ovsyanikova EA, Chapskaya YM, Bityutskaya NN, Laukhina IV. Peculiarities of academic of motivation of students with different level of Internet addiction. Intern Busin Manag. 2016; 10(16): 3345-3348. [Link]

12. Siomos KE, Dafouli ED, Braimiotis DA, Mouzas OD, Angelopoulos NV. Internet addiction among Greek adolescent students. Cyber Psychol Behav. 2008; 11(6): 653-657.

13. Shamani A, Vahedi M, Norozi D. The relationship between use of Virtual social network with cultural identity (Tehran). Couns Cult Psycother. 2017; 7(28): 19 r-ı イ r. [Persian]. [Link]

14. Salkovskis P, Jacks I. Cognitive behavioral factors and the persistence of intrusive thoughts in obsessional problems. Behav res ther. 1998; 27 (6): 677-684. [Link]

15. Badiee Aval M, Bahrami B, Rafiee Shafigh M. Comparing the Efficacy of Systematic Desensitization and expressive Desensitization on Generalized Anxiety Disorder and exam Anxiety among Students. Med j of Mashhad uni of med sci. 2021; 64(1): 22002208 [Persian]. [Link]

16. Meysami Bonab S, Abolghasemi A, Sheikhian M, Barahmand U, Rasooliazad M. The Effectiveness of Eye Movement Desensitization and Reprocessing Therapy on the Emotion Regulation and Emotion Recognition of Addicted Individuals, Zahedan J Res Med Sci. 2012; 14(10):33-37. [Persian] [Link]

17. Dashti N, Abolgasemi A. The role of self- regulation, self-presentation and dark triad personality in predicting Social Networking Sites addiction in students of Ardabil University of Medical Sciences. J Knowledge Res Applied Psychol. 2018; 2(19): 11-21. [Persian]. [Link]

18. Mei S, Yau YHC, Chai J, Guo J, Potenza MN. Problematic Internet use, well-being, self-esteem and self-control: Data from a high school survey in China. Addict Behav. 2016; 98: 75-76. [Link]

19. Gokcearslan S, Mumcu FK, Haslaman T, Cevik YD. Modelling smartphone addiction. Comput Hum Behav. 2016; 63:639-49. [Link]

20. Park JA, Park MH, Shin JH, Li B, Rolfe DT, Yoo JY, et al. Effect of sports participation on internet addiction mediated by self-control: A case of Korean adolescents. Kasetsart J Soc Sci. 2016; 37(3):164-9. [Link]

21. Lemos SL. Students' goals and self-regulation in the classroom, Int Educ Res. 1999; 31(6): 471-485.. [Link]

22. Eissa Saad MA. Self-Regulated Learning and Academic Procrastination as Predictors of Smartphone Addiction among Second Year-Middle School Learning Disabled Students. Amazonia Investiga. 2020; 9 (26): 236-243. [Link]

23. Mikaeili N, Habibi Y. Design and Test of Causal Model for Relation between Internet Addiction and Emotional Self-Regulation, Rejection Sensitivity and Online Self-Disclosure with Mediation of Social Anxiety in Students. Culture in the Islamic university. 2016; 6(20): 395-418. [Persian]. [Link] 
24. Odaci HC, Clik CB. Who are problematic Internet users? An investigation of the correlations between problematic Internet use and shyness loneliness, narcissism aggression and self-perception. J Comput Hum Behav. 2013; 29: 2382-7. [Link]

25. Pour razavi $\mathrm{S}$, Alahverdipour $\mathrm{H}$, Topchian A. Determination of the Predictive role of SelfRegulation and Self-Control on Intemperate Use of Cell Phones by Students. Sci J of Hamadan Uni of Medical Sci. 2015; 22(2): 152-160. [Persian]. [Link]

26. Larose R, Lin CA, Eastin MS. Unregulated internet usage: addiction, habit, or deficient selfregulation? Media Psychol. 2003; 5:225-253. [Link]

27. Zamani Ab Nili, Farzaneh and Gorji, Yousef, , The effectiveness of emotional self-regulation training on reducing Internet addiction in female adolescents in Isfahan, the first national conference on futures studies, educational sciences and psychology, Shiraz 1400. [Link]
28. Young KS. Internet Addiction: The Emergence of a New Clinical Disorder. Cyberpsychol Behav. 1998; 1(3): 237-244. [Link]

29. Alavi SS, Islami M, Marathi MR, Najafi M, Janatifard F, Rezapour H. Psychometric properties of the Young Internet addiction test. J Behav Sci. 2010; 4(3): 183189. [Persian]. [Link]

30. Kazemian k, Mehrabi Zadeh M, Soudani M. Evaluation of the effectiveness of regular desensitization method on test anxiety and academic performance. J Wom Stud. 2006; 6(1): 123-139. [Persian]. [Link]

31. Ghare Aghaji S, Vahedi SH, Fathi Azar E, Adib Y. The effectiveness of self-regulatory, mindfulness and time management education programs on reducing procrastination and increasing academic achievement of high school students. J Edu Sci Stud. 2018; 30: 241274. [Persian]. [Link] 